\title{
Fundamentos
}

\begin{abstract}
Resumo
Nesse artigo pretende-se mostrar qual sentido e referente Winnicott atribuiu aos termos self e ego. Ainda que Winnicott não tenha usado esses termos de maneira clara e distinta ao longo de sua obra, procura-se demonstrar que, num momento mais maduro, ele caracteriza o self como um termo descritivo que se refere à experiência individual do ser, enquanto o ego apresenta dois sentidos: um mais amplo e de conotação ontológica, que o toma como uma tendência inata à integração, e outro como um conceito cujo referente é a unidade do sujeito psicológico, nos seus mais diversos graus.

Descritores: self; ego; integração; redescrição; metapsicologia.
\end{abstract}

\section{ASPECTOS DIFERENCIAIS DA NOÇÃO DE EGO E DE SELF NA OBRA DE WINNICOTT}

\author{
Leopoldo Fulgencio
}

DOl: http://dx.doi.org/10.11606/issn. 1981-1624.v19i1p183-198

()

estudo da maneira como Winnicott utiliza os conceitos e termos teóricos da psicanálise pode evidenciar a diferença significativa entre o que ele afirma e o sentido que estes têm nas suas acepções de origem (Greenberger \& Mitchell, 1983).

O termo ego, na psicanálise, tem um sentido metapsicológico consagrado, referindo-se a uma das instâncias psíquicas do segundo modelo metapsicológico do aparelho psíquico, apresentado por Freud em 1923. Winnicott, por sua vez, parece não somente modificar o sentido dado pelos psicanalistas ao termo ou conceito de ego, mas também introduz o termo ou conceito de self, raramente utilizado na psicanálise até então e que parece ter um referente próximo ao de ego (Phillips, 1988/2007, p. 120).

A questão que se coloca, necessária para o esclarecimento das contribuições de Winnicott para a teoria psicanalítica, é a de saber

- Docente do Programa de Pós-Graduação em Psicologia da Pontifícia Universidade Católica de Campinas (PUC-Campinas), São Paulo, SP, Brasil. 
qual o sentido e referente ele atribui aos termos ego e self. O próprio Winnicott reconhece a necessidade de designar com mais clareza qual sentido deve ser dado ao termo ego (Winnicott, 1987/1990a, p. 77, carta a Michael Fordham de 26/09/1955).

Como é sabido, Freud não utiliza o termo ego, mas Ich, cuja tradução mais direta para o português nos leva ao termo $e u$; cabe a Strachey a responsabilidade por ter adotado o termo latino ego como tradução para o alemão Ich, marcando, assim, com uma tonalidade médica a teorização feita por Freud ${ }^{1}$.

Winnicott considera que o uso do termo ego, na história de desenvolvimento da psicanálise, precisa ser esclarecido para que seu uso possa ser útil (Winnicott, 1987/1990a, carta para Michael Fordham em 26/09/1955). Mas a distinção entre o sentido e referente dos termos self e ego, até mesmo para o próprio Winnicott, nem sempre foi feita de forma clara e distinta: "Foi o próprio Fordham que me fez reconhecer com um choque que eu estava usando as palavras selfe 'ego' como se fossem sinônimos, o que, naturalmente não são e não podem ser” (Winnicott, 1964/1994a, p. 371, itálicos do autor).

No decorrer de sua obra encontram-se, ainda, outros termos com referentes afins, tais como me, not-me, I Am, whole person, designando outros modos de integração do indivíduo, que precisariam ser cotejados com os sentidos dados aos termos self e ego. Certamente, está fora de questão fazer aqui um trabalho filológico e conceitual exaustivo, mas sim contribuir para que esse trabalho mais amplo possa ser feito no futuro, fazendo algumas distinções esclarecedoras sobre os referentes dos termos self e ego.

Para atingir este objetivo, propõe-se: 1. retomar sinteticamente os sentidos que Freud deu ao termo Ich, em especial, diferenciando seu sentido descritivo de seu sentido especulativo; 2. analisar diversos trechos da obra de Winnicott em que ele usa os termos self e ego, mostrando as diferenças que têm em relação a Freud e também entre si; 3. explicitar que o referente atribuído ao termo ego por Winnicott não corresponde ao seu sentido tópico, especulativo, atribuído por Freud.

\section{O referente descritivo e o metapsicológico do conceito de ego em Freud}

Pode-se afirmar que Freud atribuiu dois referentes ao termo Ich: um psicológico, descritivo, designando a unidade pessoal que distingue o indivíduo do mundo; e outro metapsicológico, especulativo, referindo-se a uma instância do aparelho psíquico (ver comentário de Strachey (Freud, 1923/1976a) apresentado 
no início da tradução do artigo "O ego e o id").

Por um lado, o termo Ich é usado como descrevendo ou designando a unidade pessoal do indivíduo, tal como encontrou, inicialmente, no tratamento de pacientes histéricos; por outro, Freud considerou que esse termo devia ser referido a uma instância ou sistema de um suposto aparelho psíquico.

Ellenberger (1970, pp.141-145) mostra como a psiquiatria dinâmica, em meados do século XIX, tomou a histeria como a doença básica de referência para pensar e classificar as doenças mentais, o que esclarece qual o cenário conceitual que Freud tinha em mente quando propôs a compreensão dos mecanismos (inconscientes) que produzem os sintomas na histeria, base para compreensão da gênese de todo sintoma nas neuroses (Freud \& Breuer, 1897/1956).

Para Freud, no caso da histeria, o eu é ameaçado por ideias incompatíveis com seus valores pessoais e/ou morais-sociais - via de regra, ideias relacionadas aos desejos sexuais -, colocando em risco sua integridade e/ou produzindo grande angústia. $\mathrm{O}$ resultado desse conflito, tornado ou não inconsciente, seria a produção de sintomas, uma solução de compromisso que atendia simultaneamente aos dois polos do conflito (o $e u$ e as ideias incompatíveis com o $e u$ ). Nesse momento, claramente, o termo eu é usado no sentido descritivo, como a unidade empírica do sujeito psicológi- co. Já no "Projeto de uma psicologia para neurólogos”, Freud (1897/1995) faz uma definição do que é o $e u$ em termos metapsicológicos, como a totalidade dos investimentos do sistema neuronal (Freud, 1897/1995, p.36). Na "Interpretação dos sonhos" (Freud, 1900/2003), o eu refere-se a uma parte da totalidade do sujeito psicológico associado à consciência (eu consciente que, ao lado da censura do sonho, contribui para manter o indivíduo elaborando e transformando o material onírico e seus conteúdos durante o sono) que participa ativamente na elaboração secundária do sonho e dos conflitos a ele associados. $\mathrm{O} e u$, nesse momento, apresenta um sentido mais descritivo do que especulativo, não sendo considerado ao lado das outras instâncias (Inconsciente, Préconsciente, Consciente) como mais uma delas ou similar a elas.

Também em outros textos importantes, especialmente nos "Três ensaios sobre a sexualidade" (Freud, 1905/1976b) e em "Introdução ao narcisismo" (Freud, 1914/2005), Freud refere-se ao en em termos descritivos, sempre apontando para efetivos mecanismos de ação psíquica realizados por um sujeito psicológico em relação à suas representações e aos objetos de seu amor ou desejo.

Quando Freud postula a concepção de um aparelho psíquico subdivido em instâncias ou sistemas, ele propõe uma analogia para figurar aquilo que não é figurável, o psiquismo, descrevendo-o, então, de 
modo especulativo, como se fosse um aparelho. Ele caracteriza tal proposição como uma ficção teórica (Freud, $1900 / 2003$, p. 659) de valor apenas heurístico ou, em outra terminologia, como um conceito metapsicológico ${ }^{2}$.

Um conceito metapsicológico corresponde a uma ideia abstrata, uma convenção. $\mathrm{Na}$ verdade, um conceito que não tem, nem pode ter, um referente adequado na realidade fenomênica. No entanto, seguindo a máxima kantiana - intuições sem conceitos são inúteis (para o conhecimento científico), e conceitos sem intuições são vazios -, Freud procura preencher o conteúdo de seus conceitos metapsicológicos introduzindo neles conteúdos empíricos, descritivos e também fazendo analogias.

Sabe-se, no entanto, que em "O ego e o id”, Freud (1923/1976a) reformula a metapsicologia ao apresentar uma nova tópica para seu ficcional aparelho psíquico, acrescentando um novo sentido para o termo Ich (ego), referindo-se a ele como uma das instâncias do aparelho psíquico, ao lado do $i d$ e do superego.

A questão que se coloca sobre a origem do Ich, em termos da unidade do indivíduo com base na qual uma série de ações podem ser realizadas (inclusive o próprio recalque, fundamental para a constituição do inconsciente reprimido), não passou desapercebida por Freud, ainda que ele não tenha desenvolvido uma resposta (seja em termos metapsicológicos, seja em termos descritivos).
Em "Introdução ao narcisismo", ele afirma, referindo-se ao problema da constituição da unidade empírica do indivíduo, que

é necessário admitir que não existe desde o início, no indivíduo, uma unidade comparável ao eu; o eu deve ter um desenvolvimento. Mas as pulsões eróticas estão lá desde o início; é necessário, então, que alguma coisa, uma nova ação psíquica, venha se juntar ao autoerotismo para formar o narcisismo. (Freud, 1914/2005, p. 221)

E, no campo de uma explicação propriamente metapsicológica, no quadro da sua teoria da constituição do aparelho psíquico, Freud comenta qual seria o processo de formação dessa instância psíquica: "[o ego] é a parte do id que foi modificada sob a influência direta do mundo exterior, por intermédio do sistema percepção-consciência" (Freud, 1923/1991, pp. 268-269).

É comum Freud usar o termo Ich conjugando seu sentido descritivo com o metapsicológico (Freud, 1940/1985, p. 74). Considerando unidos os dois registros (dois sentidos ou referentes) do termo Ich (o descritivo e o metapsicológico), pode-se afirmar que, para Freud, o id existe antes do ego. Esse é um ponto fundamental para a compreensão da noção de ego e self em Winnicott, dado que é justamente na explicação dos processos iniciais referidos à integração do indivíduo em termos de um Eu que se encontram elementos para diferenciar, neste caso específico, a posição de Winnicott da de Freud. 


\section{Os referentes do conceito de ego e de self para Winnicott}

Semelhante a Freud, Winnicott também considera que o ego não existe desde o início: "A primeira pergunta que surge com respeito ao que é denominado ego é a seguinte: Há um ego desde o início? A resposta é que o início está no momento em que o ego inicia. [nota: É bom lembrar que o começo é uma soma de começos]" (Winnicott, 1965/1983a, p. 56). No início ${ }^{4}$ diz Winnicott, somente do ponto de vista do observador é que se pode referir-se à unidade ao bebê. $\mathrm{Na}$ verdade, não há apenas um bebê, mas sempre o bebê acompanhado, cuidado por alguém, um bebê e seu ambiente de sustentação. É nesse sentido que Winnicott pôde afirmar "Isso que chamam de bebê não existe ... a unidade não é do indivíduo, a unidade é o contexto ambiente-indivíduo" (Winnicott , 1958/2000d, pp. 165-166).

Winnicott, criticando Freud, inverte a formulação freudiana, considerando que "Não há id antes do ego" (Winnicott, 1965/1983a, p. 55), considerando que a suposição de haver um ego desde o início é o que estava sendo considerado pelos autores da psicologia do ego, mas que a existência desse ego inicial também deveria supor como "intimamente relacionado a um apoio do ego fornecido de modo sensível pela mãe ao bebê que tem a sorte de possuir uma mãe apoiadora do ego" (Winnicott, 1964/1994a, p. 371). Por um lado, Winnicott afirma que é da fusão com o ambiente que surgirá o ego enquanto unidade individual:

O centro de gravidade do ser não surge no indivíduo. Ele se encontra na situação global. Através do cuidado suficientemente bom, através das técnicas, da sustentação e do manejo geral, a casca passa a ser gradualmente conquistada, e o cerne (que até então nos dava a impressão de ser um bebê humano) pode começar a tornar-se um indivíduo. (Winnicott, 1958/2000d, p. 166)

Por outro lado, o autor afirma que o ego, no início, corresponde a um somatório de experiências, relacionadas tanto aos estados tranquilos como os excitados, um somatório que configura um "eu individual" (Winnicott, 1958/2000e, p. 405).

Para compreender a posição de Winnicott, sem julgá-lo incongruente ou mesmo contraditório, é necessário reconhecer os dois sentidos dados ao termo ego: uma tendência e uma unidade.

Por um lado, o ego é uma tendência inata para a integração, que dependerá, no entanto, do ambiente para que possa se efetivar: "Pode-se usar o termo ego para descrever a parte em crescimento da personalidade humana que tende, sob condições favoráveis, a se integrar em uma unidade" (Winnicott, 1965/1983a, p. 55). O ego, nesse sentido, corresponde, numa criança com o cérebro intacto 
(por oposição a uma criança anencefálica), àquela parte do indivíduo que pode apreender organizadamente, dando sentido às experiências corporais:

No corpo de um recém-nascido anencefálico podem ocorrer acontecimentos funcionais, inclusive localização instintiva, acontecimentos esses que seriam denominados vivências da função do id, se houvesse um cérebro. Poder-se-ia dizer que se houvesse um cérebro normal, haveria uma organização dessas funções, e a essa organização se poderia dar o rótulo de ego. Contudo, sem aparato eletrônico não há experiência, e consequentemente não há ego. (Winnicott, 1965/1983a, p. 55)

O ego corresponde, para Winnicott, àquilo que pode organizar, dando sentido e integrando, as diversas experiências corporais, muito antes que qualquer unidade pessoal possa ter sido alcançada. Cabe ao ego, nesse sentido de tendência, apreender e dar sentido às experiências corporais; são essas experiências corporais, assim registradas, catalogadas e interpretadas pelo funcionamento do ego que Winnicott considerará como sendo o $i d$. É nesse sentido que Winnicott afirmará que "não há id antes do ego" (Winnicott, 1965/1983a, p. 55).

Por outro lado, o ego corresponde à própria unidade integrada do sujeito psicológico, integração que acontece em diversos graus. Ao referir-se aos pacientes que tiveram os cuidados ambientais necessários para que pudessem integrar-se numa unidade psicológica, Winnicott afirma, referindo-se ao ego como esta unidade conquistada com a ajuda dos cuidados ambientais suficientemente bons:

Olhando para trás, podemos hoje perceber que os casos eram selecionados corretamente para a análise, quando a história primitiva do paciente mostrasse que ele teria sido cuidado de modo suficientemente bom. Essa adaptação inicial suficientemente boa à necessidade teria dado ao ego individual a possibilidade de ser, e como resultado, os estágios iniciais do estabelecimento do ego podiam ser considerados pelo analista um fato consumado. (Winnicott, 1956/2000b, p. 393, itálico do autor)

Nesse momento, Winnicott se refere ao ego como esta unidade, e não como uma tendência para a integração, referindo-se à neurose de transferência como uma possibilidade de relação analítica que depende da conquista desta unidade:

no momento da análise dessas fases [mais primitivas do desenvolvimento], o ego do paciente não pode ser presumido como uma entidade estabelecida. Não pode, então, existir a neurose de transferência, para a qual certamente é 
preciso que haja um ego, e na verdade um ego intacto, capaz de manter defesas conta a ansiedade derivada dos instintos - e de assumir a responsabilidade pelas mesmas. (Winnicott, 1956/2000b, p. 394)

Winnicott se refere ao ego no sentido de unidade integrada do sujeito psicológico, afirmando, por exemplo, que no início de um tratamento analítico, considera-se a colaboração do ego do paciente, ou ainda que, referindo-se a uma fase final de uma análise, que "o ego do paciente, agora independente, começa a se revelar e afirmar suas características individuais, começando o paciente a ver como natural o sentimento de existir por si mesmo" (Winnicott, 1965/1983b, p. 154).

Isso pode causar confusão, dado que Winnicott também se refere ao self como sinônimo do "sujeito objetivo, isto é, a ideia de um self, e o sentimento do real que surge do senso de ter-se uma identidade" (Winnicott, 1971/1994b, p. 140).

Assim, além de considerar o ego no como tendência e como sujeito (unidade integrada), é necessário diferenciar o ego do self. Winnicott reconhece este problema semântico-conceitual (Winnicott, 1964/1994a).

Nesse sentido, pode-se afirmar que o selfé um termo descritivo, enquanto o ego é um termo teórico (Winnicott, 1964/1994a, p. 371). Por termo teórico pode-se entender que o ego é um conceito, um nome dado a um conjunto de experiências que o indivíduo agrupa numa unidade pessoal; enquanto que ao self corresponde a experiência da unidade empírica do indivíduo na sua relação com o mundo: "Para mim o self que não é o ego é a pessoa que é eu, que é apenas eu, que possui uma totalidade baseada no processo de maturação" (Winnicott, 1971/1994c, p. 210). Seguindo o processo de amadurecimento, no início, o "bebê é não-integrado" e procura algo em algum lugar para atender às suas necessidades de ser (Winnicott, 1954/1978a , p. 340). Com a adaptação ambiental adequada, o bebê encontra o objeto que satisfaz suas necessidades. Pode-se supor, para usar um exemplo didático, que o bebê necessite mamar. Com a miríade de adaptações ambientais que uma mãe devota faz ao atender seu bebê, este, pouco a pouco, tem a experiência de encontrar o objeto que satisfaz sua necessidade ao mesmo tempo em que se integra num self que se relaciona com esse objeto. Do ponto de vista do bebê, o objeto surgiu, como se fosse derivado de sua necessidade, e poder-se-ia dizer que o bebê 
teria criado o objeto (seio) no qual mama; do ponto de vista do observador, porém, o objeto foi fornecido ao bebê. Nesse momento trata-se de, em um mesmo gesto (num mesmo conjunto de ações do bebê e de ações adaptativas do ambiente) gerar tanto o objeto subjetivo (seio) quanto o self que realiza a ação de mamar.

É na ação criativa do bebê, sustentada pelo ambiente, que surge, ao mesmo tempo, a experiência do self e o encontro com o objeto (subjetivo, criado pelo bebê). Para usar um esquema gráfico que expressa esse fato, traça-se uma curva que fornece, ao mesmo tempo, o côncavo e convexo, o self e o objeto subjetivo, ligando-os como uma criação do si mesmo em direção a esse objeto. Pergunta-se: quem faz o traço? E a resposta é: o bebê por meio da ação adaptativa adequada do ambiente.

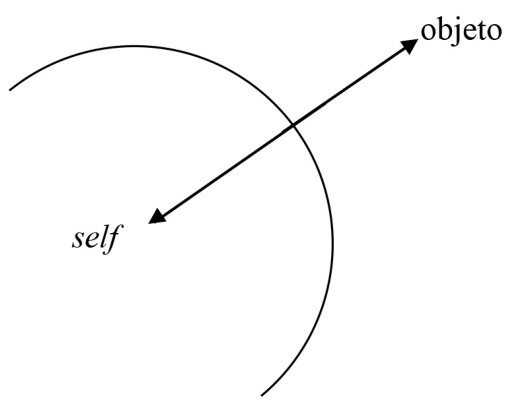

O bebê, nesse momento, tem a experiência de um self que, do ponto de vista do observador, somente existe porque o ambiente foi suficientemente bom ao adaptar-se às necessidades daquele bebê. No início, essa vivência não é contínua, mas intermitente. É a sua repetição, sustentada pelo ambiente, que tornará tal integração, ou tais integrações para ser mais preciso, mais estável (eis).

Esse self, assim experienciado, não pode ser considerado um $e u$ interno porque ainda não há dentro e fora, o bebê é uma unidade (dois em um) com a mãe (ambiente), e esse self somente existe com esse ambiente, já que o ambiente é parte constituinte do self. É nesse sentido que Winnicott afirma que o bebê, enquanto entidade em si mesma, não existe, e o que se vê é a "dupla amamentante" (Winnicott, 1958/2000d, p. 165).

Não há no início uma unidade que pudesse ser creditada somente ao indivíduo: "Nos estágios iniciais, a dependência do ambiente é tão absoluta que não há utilidade alguma em pensarmos no novo indivíduo humano como sendo ele a unidade" (Winnicott, 1988/1990b, pp. 153-154). No entanto, quando ocorre a adaptação adequada, o bebê (que procura alguma coisa em algum lugar, sem saber o que exatamente procura), via adaptação ambiente, encontra (cria) um objeto (portanto, objeto subjetivo) que atende às suas necessidades, ao mesmo tempo em que tem a experiência de que é ele mesmo (seu self) que se relaciona com esse objeto. Atendida a necessidade, no entanto, tanto o objeto quanto o self desaparecem.

A continuidade do processo de amadurecimento fornece infinitas 
experiências de si mesmo, experiências de ser, que gradativamente vão se integrar entre si. No momento seguinte ao processo de amadurecimento, o indivíduo pode agrupar todas essas experiências do self num mesmo conjunto, integrando-as e podendo se diferenciar do mundo, ou seja, a criança chega à fase do "Eu Sou" (Winnicott, 1971/1989, p.31): fase em que a criança diferencia mundo externo de mudo interno, mas ainda se mantém na dinâmica de relação caracterizável como sendo de

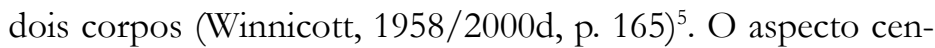
tral, visto como o motor e a linha sobre a qual se desenvolve o amadurecimento do ser humano, é a integração, ou a tendência inata à integração. Ao pensar nessa linha que levará o bebê da situação de não integração que ele vive no início às experiências de ser, experiências de ser si mesmo ou experiências de self, de conquistar um self unitário ou o status do "Eu Sou", e seguir até o momento em que o indivíduo é uma pessoa inteira que se relaciona com os outros e com si mesmo como sendo pessoas inteiras, pode-se entender de que maneira Winnicott entende a passagem do ser ao fazer: "A integração conduz o bebê ao estado de unidade, ao pronome pessoal 'je', ao número um; ela torna possível o 'eu sou', que dá sentido ao 'eu faço"' (Winnicott, $1971 / 1989$, p. 11). No processo de desenvolvimento afetivo, as primeiras experiências levam a um Sou que só mais tarde chega a um Eu Sou, bases, então, para o Eu faço.

A esta unidade da pessoa, primeira unidade Eu Sou, que diferencia o indivíduo do mundo, pode-se também denominar ego, nome atribuído a um conjunto de experiências de si mesmo (Winnicott, 1958/2000e, p. 405) que o indivíduo pode agregar como conteúdos de uma unidade, conceito que se refere ao conjunto de experiências que, juntas, o indivíduo é em sua identidade.

Winnicott considera que a chegada nesse tipo de integração e a sua manutenção constituem o aspecto central do desenvolvimento humano, com este Sou significando para a pessoa: "que tenho um sentido de existência enquanto pessoa, que sinto em meu juízo que minha existência foi provada" (Winnicott, 1984/1999, p. 43). A conquista desse estado, que não é um estado reflexivo, não é um tipo de autoconsciência, mas um tipo de experiência, um modo de estar no mundo que corresponde, para ele, algo que também produz angústia, e para o qual se deve estar preparado (algo que muitos temem): 
Se eu sou, então o caso é que consegui agrupar isto e aquilo e reivindiquei que isto sou eu, e que repudiei todo o resto; ao repudiar o não eu, insultei o mundo, por assim dizer, e posso aguardar um ataque. (Winnicott, 1984/1999, p. 43$)^{6}$

$\mathrm{Na}$ continuidade do processo de amadurecimento, esse tipo de integração Eu Sou se torna cada vez mais complexo, com a integração do bem e do mal, dos sentimentos ambivalentes, da possibilidade de reconhecer o agressor e de realizar a reparação. Ao final desse novo período de integração, a criança chega à integração caracterizável por Winnicott como a de uma pessoa inteira (Winnicott, 1988/1990b, Parte II) que se relaciona com os outros como pessoas inteiras (no quadro do cenário edípico e na administração da vida instintual nas suas relações interpessoais). A essa integração como pessoa inteira (cuja dinâmica está referida ao relacionamento a três corpos) também é possível, no pensamento de Winnicott, denominar como o ego do indivíduo. As pessoas que chegam a essa conquista "funcionam em termos de pessoa inteira, cujas dificuldades localizam-se no reino dos relacionamentos interpessoais" (Winnicott, 1955/1978b, p. 375); tratam-se, em outra linguagem, de pessoas que puderam chegar à posição depressiva, ou seja, para Winnicott, para alcançar a posição depressiva, "o bebê deve ter conseguido estabelecer-se como uma pessoa inteira, e relacionar-se com pessoas inteiras 
enquanto pessoa inteira" (Winnicott, 1955/2000a, p. 357).

O processo de integração é a base para o desenvolvimento saudável, levando o indivíduo a identificações cada vez mais amplas. Partindo da situação inicial em que o bebê e o ambiente são um tipo de amálgama, tendo experiências de ser e de ser a partir de si mesmo (a partir do self) $)^{7}$, passando pelo momento em que ele e o mundo se juntam e se separam (ao viver os fenômenos transicionais), chegando à primeira distinção que separa mais claramente o Eu do Não Eu (com a conquista, na saúde, do status de unidade na fase do Eu Sou), em que o indivíduo passa, então, a ter efetivas relações, mais fidedignamente caracterizadas como relações a dois corpos, até que, com uma série de outras integrações (da instintualidade, dos impulsos amorosos e destrutivos, com a possibilidade de realizar o ciclo benigno), o indivíduo chega ao status de pessoa inteira, vivenciando os problemas da administração dos instintos nas relações interpessoais (relações a três corpos, marcadas pela sexualidade e pelo cenário edípico que organiza e torna conflituosas as relações).

Afirma Winnicott, nesse sentido, que:

O estado de unidade é a conquista básica para a saúde no desenvolvimento emocional de todo ser humano. Com base nesse estado, a personalidade unitária pode permitir a identificação com unidades mais amplas - digamos, a família, o lar ou a casa. (Winnicott 1984/1999, p. 47)
Pode-se acrescentar que essa afirmação é válida também para outros agrupamentos sociais até a pertinência mais ampla de sentir-se um cidadão do mundo.

\section{Considerações finais}

Em resumo, retomando o conjunto de diferenciações feitas, pode-se dizer que ao self corresponde um tipo de vivência e experiência singular; ao ego, termo usado para referir-se a uma tendência (à integração) que caracterizaria a própria estrutura ontológica do ser humano e também à unidade individual integrada (agrupando um conjunto de experiências num nome), um conceito que se refere ao conjunto de experiências individuais integradas numa unidade ${ }^{8}$; e a expressão pessoa inteira corresponde à chegada do indivíduo a um modo de organização em que ele precisa administrar sua vida instintual (sexual) nas suas relações interpessoais, vivendo e procurando soluções (mais ou menos patológicas) aos conflitos que derivam de fazer a vida com os outros.

Em termos das experiências de si mesmo, pode-se afirmar que o indivíduo segue uma linha que vai do Sou para o Eu Sou, que embasa o Eu Faço, seguindo em direção, na saúde, a um Eu sou uma pessoa inteira que se relaciona com pessoas inteiras, caminhando para um horizonte cada vez mais amplo (sempre sujeito a instabi- 
lidades, regressões e progressões também dependentes do ambiente e da situação ambiental) do Eu sou um cidadão do mundo.

Nenhum desses termos ou conceitos utilizados por Winnicott (self, ego, Eu Sou, pessoa inteira) corresponde a uma proposição metapsicológica, no sentido de considerar um ou outro como um sistema de um ficcional aparelho psíquico, tal como Freud (1923/1976a) propôs em sua teorização metapsicológica da segunda tópica. No entanto, como apontou Martine Girard (2010), há que se considerar que a maneira como Winnicott descreve o funcionamento da existência psicossomática, haveria que se supor que ele estaria considerando outra tópica, dado que ele estaria diferenciando integrações e modos de funcionamento dos indivíduos, com funções e posições díspares (2010). Por um lado, as diferenciações terminológicas e conceituais feitas até o momento (em relação aos termos self, ego, Eu Sou, pessoa inteira) corroboram essa afirmação de que deve-se considerar outra tópica, para explicar e compreender o funcionamento do indivíduo; por outro lado, Winnicott não considera esses termos especulações, no sentido em que Freud usa suas construções auxiliares, um tipo de superestrutura especulativa teórica da psicanálise; Winnicott os toma efetivamente como possuidores de referentes empíricos na realidade factual. É nesse sentido que, talvez, possamos compreender, ao menos nesse caso, como Winnicott redescreve Freud à sua maneira, sendo freudiano na base, mas modificando suas teorizações. DIFFERENTIAL ASPECTS OF THE NOTION OF EGO AND SELF IN
WINNICOTT'S WORK

\begin{abstract}
The purpose of this article is to examine the meaning and referent given by Winnicott to the terms self and ego. Although Winnicott didn't use these terms clearly in his work, what we try to show here is that in a more mature moment, he presents the self as a descriptive term which refers to the individual experience of being whereas the ego has two meanings: one which is more comprehensive and has an ontological connotation, with an inborn tendency towards integration, and the other as a concept having as referent the unit of the psychological subject on different levels.
\end{abstract}

Index terms: self; ego; integration; redescription; metapsychology.

ASPECTOS DIFERENCIALES DE LA NOCIÓN DE EGO Y DE SELF EN LA OBRA DE WINNICOTT

\footnotetext{
RESUMEN

El objetivo de este articulo es estudiar el sentido y referente que Winnicott dio a los términos self y ego. Aunque Winnicott no los utilice de manera clara y distinta en su obra, se busca demostrar que, en un momento más maduro, él caracteriza el self como un término descriptivo que se refiere a la experiencia individual del ser; ego, en cambio, tiene dos sentidos: uno más amplio y de connotación
}

194 Estilos clin., São Paulo, v. 19, n. 1, jan./abr. 2014, 183-198. 
ontológica que lo considera como una tendencia innata a la integración, y otro, como un concepto que tiene como referente la unidad del sujeto psicológico, en sus distintos grados.

Palabras claves: self; ego; integración; redescripción; metapsicología.

\section{REFERÊNCIAS}

Ellenberger, H. F. (1970). The discovery of the unconscious. The history and evolution of dynamic psychiatry. New York: Basic Books.

Freud, S. (1976a). O ego e o id. In S. Freud, Edição standard brasileira das obras psicológicas completas de Sigmund Freud (J. Salomão, trad., Vol.19, pp.13-83). Rio de Janeiro: Imago. (Trabalho original publicado em 1923)

Freud, S. (1976b). Três ensaios sobre a teoria da sexualidade. In S. Freud, Edição standard brasileira das obras psicologicas completas de Sigmund Freud (J. Salomão, trad., Vol. 7, pp. 123-250). Rio de Janeiro: Imago. (Trabalho original publicado em 1905)

Freud, S. (1985). Abrégé de psychanalyse. Paris: PUF. (Trabalho original publicado em 1940)

Freud, S. (1991). Le moi et le ça. In S. Freud, Oeuvres complètes (Vol. 16, pp. 255-301). Paris: PUF. (Trabalho original publicado em 1923)

Freud, S. (1995). Projeto de uma psicologia (O. F. G. Junior, trad.). Rio de Janeiro: Imago. (Trabalho original publicado em 1897)

Freud, S. (2003). L'intrepretation des rêves. In S. Freud, Oeuvres complètes 1899-1900 (Vol. 4, pp. 7-756). Paris: PUF. (Trabalho original publicado em 1900)

Freud, S. (2005). Pour introduire le narcissisme. In S. Freud, Oeuvres complètes $1913-$ 1914 (Vol. 12, pp. 213-245). Paris: PUF. (Trabalho original publicado em 1914)

Freud, S., \& Breuer, J. (1956). Etudes sur l'bysterie. Paris: PUF. (Trabalho original publicado em 1897)

Fulgencio, L. (2003). As especulações metapsicológicas de Freud. Revista de Filosofia e Psicanálise Natureza Humana, 5 (1), 127-164.

Fulgencio, L. (2007). Winnicott's rejection of the basic concepts of Freud's metapsychology. International Journal of Psychoanalysis, 88 (2), 443-461.

Fulgencio, L. (2008). O método especulativo em Freud. São Paulo: EDUC.

Girard, M. (2010). Winnicott's foundation for the basic concepts of Freud's metapsychology? The International Journal of Psychoanalysis, 91 (2), 305-324.

Greenberger, J. R., \& Mitchell, S. A. (1983). Relacões objetais na teoria psicanalítica. Porto Alegre, RS: Artes Médicas.

Phillips, A. (2007). Winnicott. São Paulo: Idéias \& Letras. (Trabalho original publit cado em 1988)

Winnicott, D. W. (1978a). A mente e sua relação com o psique-soma. In D. W. Winnicott, Dapediatria à psicanálise (pp. 332-346). Rio de Janeiro: Francisco Alves. (Trabalho original publicado em 1954)

Winnicott, D. W. (1978b). Aspectos clínicos e metapsicológicos da regressão no contexto psicanalítico. In D. W. Winnicott, Da pediatria à psicanálise (pp. 374-392). Rio de Janeiro: Francisco Alves. (Trabalho original publicado em 1955)

Winnicott, D. W. (1983a). A integração do ego no desenvolvimento da criança. In D. W. Winnicott, O ambiente e os processos de maturação (pp. 55-61). Porto Alegre, RS: Artmed. (Trabalho original publicado em 1965) 
Winnicott, D. W. (1983b). Os objetivos do tratamento psicanalítico. In D. W. Winnicott, $O$ ambiente e os processos de maturação (pp. 152-155). Porto Alegre, RS: Artes Médicas. (Trabalho original publicado em 1965)

Winnicott, D. W. (1983c). A capacidade para estar só. In D. W. Winnicott, $O$ ambiente e os processos de maturação (pp. 31-37). Porto Alegre, RS: Artmed. (Trabalho original publicado em 1958)

Winnicott, D. W. (1989). O conceito de indivíduo saudável. In $\mathrm{D}$. W. Winnicott, Tudo comę̧a em casa (pp. 3-22). São Paulo: Martins Fontes. (Trabalho original publicado em 1971)

Winnicott, D. W. (1990a). O gesto espontâneo. São Paulo: Martins Fontes. (Trabalho original publicado em 1987)

Winnicott, D. W. (1990b). Natureza Humana. Rio de Janeiro: Imago. (Trabalho original publicado em 1988)

Winnicott, D. W. (1994a). Resenha de Memories, dreams, reflections, de C.J. Jung. In D. W. Winnicott, Explorações psicanalíticas (pp. 365-372). Porto Alegre, RS: Artes Médicas. (Trabalho original publicado em 1964)

Winnicott, D. W. (1994b). Os elementos masculinos e femininos cindidos encontrados em homens e mulheres. In D. W. Winnicott, Explorações psicanalíticas (pp. 134-144). Porto Alegre, RS: Artes Médicas. (Trabalho original publicado em 1971)

Winnicott, D. W. (1994c). As bases para o si mesmo no corpo. In D. W. Winnicott, Explorações psicanalíticas (pp. 203-218). Porto Alegre, RS: Artmed,. (Trabalho original publicado em 1971)

Winnicott, D. W. (1994d). A enfermidade psicossomática em seus aspectos positivos e negativos. In D. W. Winnicott, Explorações psicanalíticas (pp.82-90). Porto Alegre, RS: Artes Médicas. (Trabalho original publie cado em 1964)

Winnicott, D. W. (1994e). Uma nova luz sobre o pensar infantil. In D. W. Winnicott, Explorações psicanalíticas (pp. 119-123). Porto
Alegre, RS: Artes Médicas. (Trabalho oriA ginal publicado em 1965)

Winnicott, D. W. (1994f). Pós-escrito: D.W.W. sobre D.W.W. In D. W. Winnicott, Exploraçõespsicanalíticas (pp.433-443). Porto Alegre, RS: Artes Médicas. (Trabalho original publicado em 1967)

Winnicott, D. W. (1994g). O uso do objeto no contexto de Moisés e o monoteísmo (Parte VII do cap. 34). In D. W. Winnicott, Explorações psicanalíticas (pp. 187-191). Porto Alegre, RS: Artes Médicas,. (Trabalho original publicado em 1969)

Winnicott, D. W. (1999). Sum: eu sou. In D. W. Winnicott, Tudo comeca em casa (pp. 4151). São Paulo: Martins Fontes. (Trabalho original publicado em 1984)

Winnicott, D. W. (2000a). A posição depressiva no desenvolvimento emocional normal. In D. W. Winnicott, Da pediatria à psicanálise: obras escolbidas (pp. 355-373). Rio de Janeiro: Imago Ed., 2000. (Trabalho original publit cado em 1955)

Winnicott, D. W. (2000b). Formas clínicas da transferência. In D. W. Winnicott, Da pediatria à psicanálise: obras escolbidas (pp. 393-398). Rio de Janeiro: Imago. (Trabalho original publicado em 1956)

Winnicott, D. W. (2000c). A reparação relativa à defesa organizada da mãe contra a depressão. In D. W. Winnicott, Da pediatria à psicanálise: obras escolbidas (pp. 156-162). Rio de Janeiro: Imago. (Trabalho original publicado em 1958)

Winnicott, D. W. (2000d). Ansiedade associada à insegurança. In D. W. Winnicott, Da pediatria à psicanálise: obras escolbidas (pp. 163-167). Rio de Janeiro: Imago. (Trabalho original publicado em 1958)

Winnicott, D. W. (2000e). A preocupação materna primária. In $\mathrm{D}$. W. Winnicott, $D a$ pediatria à psicanálise: obras escolbidas (pp. 399405). Rio de Janeiro: Imago. (Trabalho original publicado em 1958) 


\section{NOTAS}

1. Ao analisar a posição de Freud, serão usados os termos ego e en como traduções do termo alemão Ich e, portanto, como sinônimos. No entanto, reservarei, preferencialmente, o termo eu para quando fizer referência aos aspectos descritivos desse conceito, e o termo ego, para os aspectos mais metapsicológicos do termo, escolhendo um ou outro em função do contexto em que estiver analisando as posições de Freud. Quando estiver analisando as concepções de Winnicott utilizarei os termos self, ego, 'Eu Sou'e 'pessoa inteira', explicitando os sentidos específicos de cada um deles.

2. Em Fulgencio $(2003,2008)$ há uma análise sobre a natureza e a função da metapsicologia em Freud; bem como um diálogo, em curso no International Journal of Psychoanalysis, sobre o lugar da metapsicologia na obra de Winnicott (Fulgencio, 2007; Girard, 2010).

3. Para explicar como o id pode começar a existir (como uma instância psíquica), Freud supõe a existência de um "recalque originário", que seria um mecanismo onde certos conteúdos se agregam, se atraem, aglutinando-se e constituindo este "lugar" para o qual o recalcamento propriamente dito poderia enviar os conteúdos reprimidos. Não caberia aqui uma discussão sobre o "recalque originário", mas tão somente a referência ao processo que pode jogar alguma luz sobre o sentido do termo Ich em Freud.

4. Pode surgir, aqui, uma dúvida, quanto a saber o que deve ser considerado como o início. Toma-se, como caracterização e referente do que pode ser considerado como início, aquilo que Winnicott afirma como sendo a experiência de ser: "Gostaria de postular um estado de ser que é um fato no bebê normal, antes do nascimento e logo depois. Esse estado de ser pertence ao bebê, e não ao observador. A continuidade do ser significa saúde. Se tomarmos como analogia uma bolha, podemos dizer que quando a pressão externa está adaptada à pressão interna, a bolha pode seguir existindo. Se estivéssemos falando de um bebê humano, diríamos 'sendo'. Se por outro lado, a pressão no exterior da bolha for maior ou menor do que aquela em seu interior, a bolha passará a reagir à intrusão. Ela se modifica como reação a uma mudança no ambiente, e não a partir de um impulso próprio. Em termos do animal humano, isto significa uma interrupção no ser, e o lugar do ser é substituído pela reação à intrusão" (1988/1990b, p. 148).

5. Essa relação a dois corpos corresponde a um tipo de amadurecimento ou integração que advém da relação inicial em que "a unidade não é o indivíduo, a unidade é o contexto ambiente-indivíduo" (Winnicott, 1958/2000d, p. 166). Na continuidade do processo de integração, conquistada essa possibilidade de relação a dois corpos, a criança pode, então, progredir em direção ao amadurecimento que a levará à possibilidade de relacionamentos interpessoais em termos de triádicos, relação a três corpos (Winnicott, 1958/1983c, p. 32).

6. Às vezes Winnicott se refere a esse estado de integração, anteriormente referido ao Eu Sou, como o de um self unitário (Winnicott, 1984/1999, p. 47), o que mostra também que nem sempre a terminologia utilizada pelo autor é clara e distinta. O trabalho de distinção desenvolvido neste artigo corresponde a uma maneira de tentar interpretar que diferentes tipos de referentes são fornecidos pelo autor a esses termos.

7. A discussão sobre a diferenciação entre o falso e o verdadeiro self não foi abordada no trabalho, uma vez que se preferiu manter, para fins de análise da diferenciação entre o self e o ego em Winnicott, um enfoque do self quase como sinônimo de self verdadeiro. Entende-se, contudo, que esse aspecto do problema exigiria um desenvolvimento mais preciso. 
8. Vale ressaltar que o presente trabalho não desconsidera a tentativa de Winnicott de discriminação dos termos feita em suas teorizações mais tardias, posteriores a 1964. No entanto, mantém-se, para este trabalho, a avaliação de que o autor, mesmo reconhecendo a confusão no uso dos termos ego e self e, mesmo que tenha considerado o termo ego como um termo teórico em oposição ao self, como um termo descritivo (Winnicott, 1964/1994a), a referência explícita ao ego como uma tendência (Winnicott, 1965/1983a) e o uso do termo ego como a unidade do sujeito psicológico ou como uma integração associada a esta unidade do sujeito psicológico (1964/1994d, p. 89; 1965/1994e, p. 120; 1967/1994f, p. 435; 1969/1994g, p. 189, por exemplo) permanece, ainda que em algumas passagens citadas, o termo ego possa conjugar esses referentes.

leopoldo.fulgencio@gmail.com

Rua Marcos Azevedo, 93

05428-050 - São Paulo - SP - Brasil.

Recebido em marco/2013.

Aceito em janeiro/ 2014.

198 Estilos clin., São Paulo, v. 19, n. 1, jan./abr. 2014, 183-198. 